\section{Frequency and risk factors associated with non-alcoholic fatty liver disease in patients with type 2 diabetes mellitus}

\author{
Frequência e fatores de risco associados à doença hepática \\ gordurosa não alcoólica em pacientes com diabetes melito tipo 2
}

Vera S. G. Ferreira', Ricardo B. Pernambuco', Edmundo P. Lopes', Clarice N. Morais ${ }^{2}$, Marbiana C. Rodrigues ${ }^{3}$, Maria Juliana Arruda', Lidiane Moura e Silva', Lucio Vilar ${ }^{1}$

\begin{abstract}
Objective: To evaluate the frequency of non-alcoholic fatty liver disease (NAFLD) in patients with type 2 diabetes mellitus (DM2) and to describe its risk factors. Subjects and methods: Blood samples of 78 patients were collected for assessment of glycemic and lipid profile, liver enzymes, TNF- $\alpha$ and HOMA-IR. The diagnosis of NAFLD was established by ultrasound. Results: NAFLD was observed in $42 \%$ of patients who had greater BMI $(p<0.001)$, and frequency of hypertension $(p<0.001$ ). Metabolic syndrome was more frequent in those with NAFLD $(p=0.019)$. The levels of aspartate, alanine aminotransferase, $\gamma$-glutamyl transpeptidase, uric acid, TNF- $\alpha$, insulin and HOMA-IR were significantly higher in patients with NAFLD than those without NAFLD. Conclusion: Almost half of patients with DM2 were found to have NAFLD, and they have more elevated BMI, as well as higher levels of aminotransferases, $\gamma-\mathrm{GT}$, uric acid, TNF- $\alpha$, insulin and HOMA-IR than subjects without NAFLD. Arq Bras Endocrinol Metab. 2010;54(4):362-8
\end{abstract}

\section{Keywords}

NAFLD; diabetes mellitus; insulin resistance; HOMA-IR; TNF- $\alpha$

\section{RESUMO}

Objetivo: Avaliar a frequência de doença hepática gordurosa não alcoólica (DHGNA) em pacientes com diabetes mellitus tipo 2 (DM2) e descrever seus fatores de risco. Sujeitos e métodos: Amostras de sangue foram coletadas de 78 pacientes para avaliação dos perfis glicídico e lipídico, enzimas hepáticas, TNF- $\alpha$ e HOMA-IR. 0 diagnóstico de DHGNA foi estabelecido por ultrassonografia. Resultados: NAFLD foi observada em $42 \%$ dos pacientes que apresentaram maior IMC $(p<0,001)$. Hipertensão arterial sistêmica $(p<0,001)$ e síndrome metabólica foram mais frequentes naqueles com DHGNA $(p=0,019)$. Os níveis de aspartato aminotransferase, alanina aminotransferase, $\gamma$-glutamil transpeptidase, ácido úrico, TNF- $\alpha$, insulina e HOMA-IR foram significativamente maiores nos pacientes com do que naqueles sem DHGNA. Conclusão: Quase metade dos pacientes com DM2 apresentaram DHGNA, os quais tiveram IMC mais elevado, bem como maiores níveis de aminotransferases, $\gamma-\mathrm{GT}$, ácido úrico, TNF- $\alpha$, insulina e HOMA-IR do que os indivíduos sem DHGNA. Arq Bras Endocrinol Metab. 2010;54(4):362-8

\section{Descritores}

DHGNA; diabetes melito; resistência insulínica; HOMA-IR; TNF- $\alpha$

\section{INTRODUCTION}

$\mathrm{N}$ on-alcoholic fatty liver disease (NAFLD) is considered one of the most common liver diseases in the Western world affecting around one third of the general population and may be linked to conditions of insulin resistance (IR) such as type 2 diabetes mellitus (DM2), obesity, and dyslipidemia (1).

Furthermore, the current prevalence of DM2 has reached epidemic proportions and it is estimated that 20 million people in the United States have DM2 while 
a further 5 million remain undiagnosed (2). In Brazil, close to $8 \%$ of the population suffer from DM2 and the incidence is steadily increasing (3). Even if estimations for the prevalence of obesity in the year 2030 remain stable, the number of diabetic patients is bound to double as a consequence of an overall increase in the age of the population and in urbanization (4).

NAFLD is characterized by the accumulation of liver fat without the consumption of alcohol (5). Obtaining knowledge regarding its actual prevalence is somewhat difficult since the great majority of patients is asymptomatic. Diagnosis is based on imaging methods (ultrasonography, CT scan or magnetic resonance imaging), although, the gold standard method is histopathology. Histopathological aspects vary from simple steatosis (the presence of fat in more than $5 \%$ of the hepatocytes) to steatosis associated to inflammation (steatohepatitis), which may evolve into progressive fibrosis, cirrhosis, and hepatocellular carcinoma (6). Physiopathology is linked to IR in the liver, muscles, and adipose tissue, associated to lipid accumulation in ectopic sites, a condition referred to as lipotoxicity. In many cases of NAFLD, the risk of developing metabolic and cardiovascular morbidities is much higher than other liver diseases (7).

NAFLD is considered to be a hepatic expression of metabolic syndrome (MS) and recent studies have pointed to DM2 as an aggravating factor for liver fibrosis irrespective of other MS factors $(8,9)$. Liver disease in patients with NAFLD and DM2 is more intense and carries a greater risk of developing into cirrhosis and a higher mortality rate $(10,11)$.

A population study in Verona found that liver disease was a relevant cause of death in patients with DM2. Other studies have revealed that the association of diabetes with NAFLD also constitutes a cardiovascular risk factor leading to IR in the myocardium and coronary dysfunction (12-14). A further study found a greater association between renal disease and NAFLD in DM2 patients (15).

The diagnosis of NAFLD in patients with DM2 is not only fundamental for the prevention of hepatic complications but also cardiovascular and renal impairment. Thus, the aim of this study is to evaluate the frequency of NAFLD in patients with DM2 and to describe the risk factors involved.

\section{SUBJECTS AND METHODS}

\section{The study population}

A total of 102 DM2 patients of both sexes, over 18 years of age, from the diabetes clinic at the Hospital das
Clínicas (HC), Universidade Federal de Pernambuco (UFPE) were included in the study. They were screened during the period from July to December 2007.

The following exclusion criteria were adopted: consumption of alcohol $>20 \mathrm{~g} /$ day for males and $>10$ $\mathrm{g} /$ day for females; the use of hepatotoxic drugs, such as corticosteroids, amiodarone, isoniazid or tamoxifen; markers for hepatitis B (HBsAg) or hepatitis C (anti$\mathrm{HCV}$ ) positive and the presence of any other liver disease, such as Schistosoma mansoni infection $(2,5)$.

Twenty four patients $(24 \%)$ were excluded from the study, including 11 with periportal fibrosis resulting from Schistosoma mansoni infection confirmed through ultrasound scan (US), 4 presented viral markers for hepatitis, and 9 abandoned the study, thus, leaving a total of 78 patients. The study was approved by the Research Ethics Committee at the Center for Health Sciences of the UFPE. All selected patients were supplied with the relevant information in easily understandable language, after which they signed the Terms of Consent and Clarification.

\section{Methods}

A standard questionnaire was applied by one researcher only in order to obtain details concerning age, sex, alcohol consumption, smoking and exercise. During the physical examination, overweight or obese patients were characterized by body mass index $(\mathrm{BMI})>25$ or $>30$ $\mathrm{kg} / \mathrm{m}^{2}$, respectively. Waist and hip measurements were also conferred, and visceral obesity was defined according to the waist/hip ratio $\geq 0.90$ in males and $\geq 0.80$ in females (16). Blood pressure was also taken with the patient in the supine position and levels above 130/85 $\mathrm{mmHg}$ were considered indicative of hypertension (17).

All patients were submitted to a US performed by the same researcher, using an Aloka SSD 500 device with a $3.5 \mathrm{MHZ}$ convex transducer to diagnose NAFLD. Criteria for diagnosing NAFLD were higher levels of echogenicity in the liver than in the renal cortex and spleen, hepatic US wave attenuation, poor definition of the diaphragm and a poor outline of the intrahepatic vascularization (18).

Blood samples were taken from peripheral veins, and sent to the Central Laboratory at the HC-UFPE, where the below-mentioned tests were carried out.

To determine the levels of the following substances, Abbott ${ }^{\circledR}$ reagents were used with the respective methods: blood glucose with hexokinase; cholesterol with estera- 
se oxidase, triglycerides with oxidase and uric acid with colorimetric uricase. For HDL cholesterol (HDL-c), DiaSys reagent and precipitation methodology were employed and for LDL cholesterol (LDL-c) the Friedwald formula was employed. Glycated hemoglobin ( $\mathrm{HbAlc})$ was determined through colorimetry, using the method described by Zander and cols. (19).

Insulin level in serum samples was determined using the microparticle enzyme immunoassay (MEIA), Abbott AxSYM ${ }^{\circledR}$ system. The degree of IR was assessed using HOMA-IR (Homeostasis model assessment of insulin resistance), as previously described and the cutoff value for HOMA-IR was 2.5 (20).

Alanine aminotransferase (ALT); aspartate aminotransferase (AST); total bilirubin and direct bilirubin; alkaline phosphatase (AP) and gamma-glutamyl transpeptidase $(\gamma-\mathrm{GT})$ were determined with an automated kinetic method $\left(\right.$ Abbott $\left.^{\circledR}\right)$.

The international normalized ratio of prothrombin time (INR) was determined with ISI and PT-Fib recombinant reagent and processed in an ACL 3000 apparatus with factory ISI. Ferritin was measured using the DiaSys reagent and employing chemiluminescent microparticle immunoassay methodology (CMIA).

Tumor Necrosis Factor Alpha (TNF- $\alpha$ ) was measured with EIA using Quantikine Human TNF $\alpha$ /TNFSFlA Immunoassay.

MS components were determined according to the International Diabetes Federation: central obesity (waist $\geq 90 \mathrm{~cm}$ for males or $\geq 80 \mathrm{~cm}$ for females), associated with at least two of the following features (17): Glucose levels $\geq 100 \mathrm{mg} / \mathrm{dL}$ or use of drugs for hyperglycemia - (in the present study all patients fulfill this criteria since they had diabetes mellitus); Triglyceride levels $>150 \mathrm{mg} / \mathrm{dL}$ or treatment for hypertriglyceridemia; HDL cholesterol levels $<40 \mathrm{mg} / \mathrm{dL}$ in males and $<50 \mathrm{mg} / \mathrm{dL}$ in females; Blood pressure $>130 / 85$ $\mathrm{mmHg}$ or specific treatment.

\section{Statistical analysis}

With the aim of characterizing the sample studied relative (\%) and absolute (N) frequencies were employed for all classes of each qualitative variable. In order to verify the differences between the groups of different categories, the Pearson Chi-square test or the Fisher's Exact Test were employed.

Mean values, standard deviations, minimums and maximums were used to indicate the quantitative variables of the data. In order to compare the groups, the Mann-Whitney nonparametric test was applied to the variables: insulin, bilirubin, $\mathrm{HbA}_{1} \mathrm{c}$, ferritin, fasting plasma glucose, AST, ALT, the AST/ALT ratio, $\gamma$-GT, post-prandial plasma glucose, HOMA-R, and TNF- $\alpha$, since these did not present normal distribution.

The Student t-test was applied to the remaining quantitative variables.

Results considered statistically significant were those with descriptive values ( $\mathrm{p}$-values) less than 0.05 ; and a confidence interval of $95 \%$.

For the technical analysis the following software were employed: MSOffice Excel 2003 to administer the database, and "Statistical Package for the Social Sciences - SPSS for Windows 12.0" to execute the statistical data, and to create and edit the graphs.

\section{RESULTS}

Of the 78 patients evaluated, $54(69 \%)$ were female and $24(31 \%)$ were male, the mean age was 57 years, with a variation of 31 to 77 years; 33 patients $(42 \%)$ presented NAFLD. In relation to the qualitative variables such as sex, alcohol consumption, smoking, exercise and hypertension, only hypertension was more frequent $(\mathrm{p}<0.001)$ amongst patients with NAFLD (Table 1$)$.

Table 1. Details illustrating clinical characteristics, demographics, habits and co-morbid conditions of 78 patients with type 2 diabetes mellitus, divided into two groups with and without non-alcoholic fatty liver disease (NAFLD)

\begin{tabular}{lllll}
\hline & & \multicolumn{2}{c}{ NAFLD } & \\
\cline { 3 - 3 } Variables & N total = 78 & $\begin{array}{c}\text { Absent } \\
(\mathbf{n = 4 5})\end{array}$ & $\begin{array}{c}\text { Present } \\
(\mathbf{n = 3 3})\end{array}$ & p-value \\
\hline $\begin{array}{c}\text { Sex } \\
\text { Female }\end{array}$ & $54(69.2 \%)$ & $31(68.9 \%)$ & $23(69.7 \%)$ & $0.939^{\circ}$ \\
$\begin{array}{c}\text { Alcohol } \\
\text { No }\end{array}$ & $69(88.5 \%)$ & $39(86.7 \%)$ & $30(90.9 \%)$ & $0.726^{\mathrm{F}}$ \\
$\begin{array}{c}\text { Smoking } \\
\text { No }\end{array}$ & $74(94.9 \%)$ & $43(95.6 \%)$ & $31(93.9 \%)$ & $>0.999^{\mathrm{F}}$ \\
$\begin{array}{c}\text { Exercise } \\
\text { No }\end{array}$ & $42(53.8 \%)$ & $22(48.9 \%)$ & $20(60.6 \%)$ & $0.305^{\circ}$ \\
$\begin{array}{c}\text { Hypertension } \\
\text { Yes }\end{array}$ & $52(66.7 \%)$ & $22(48.9 \%)$ & $30(90.9 \%)$ & $<0.001^{\mathrm{F}}$ \\
\hline
\end{tabular}

F: Fisher's Exact Test; Q: Pearson Chi-square test.

Patients with NAFLD presented higher weight $(\mathrm{p}<0.001)$; BMI $(\mathrm{p}<0.001)$, waist measurement $(\mathrm{p}$ $<0.001)$ and hip measurement $(\mathrm{p}<0.001)$ than those without NAFLD, however, there was no significant difference between the waist to hip ratio (Table 2).

Analyzing the weight utilizing the normality limits, it was confirmed that the majority (97\%) of the patients with NAFLD were either overweight or obese $(\mathrm{p}=0.006)$. 
A higher percentage of MS was encountered amongst those with NAFLD than those without NAFLD (94\% vs. $73 \%$; $\mathrm{p}=0.019$ ).

As shown in table 3 , the values of AST $(\mathrm{p}=0.006)$, $\operatorname{ALT}(\mathrm{p}=0.002), \gamma$-GT $(\mathrm{p}=0.001)$, uric acid $(\mathrm{p}=$ $0.04 \mathrm{l})$, insulin ( $\mathrm{p}=0.004)$, and HOMA-IR ( $\mathrm{p}=0.007)$ were significantly higher in patients with NAFLD than in those without NAFLD $(\mathrm{p}=0.007)$. Triglycerides levels $(\mathrm{p}=0.06)$ and TNF- $\alpha(\mathrm{p}=0.052)$ tended to be higher in subjects with NAFLD. In contrast, there was no difference in cholesterol profile nor in the levels of plasma fasting or post-prandial glucose, $\mathrm{HbAlc}, \mathrm{AP}$, bilirubins, INR or ferritin in both groups (Table 3 ).

When laboratory data was analyzed utilizing the normal limits, or rather, the frequency of normal or altered exams, it was confirmed that the serum levels of triglycerides $(p=0.012)$, insulin $(p=0.029)$, and HOMA-IR ( $\mathrm{p}=0.007$ ) were more frequently altered in those with NAFLD. There was a tendency for the AST /ALT ratio $>1(p=0.053)$ and the blood levels of ferritin ( $\mathrm{p}=0.056)$ to be more frequently altered in patients with NAFLD (Table 4).

Table 2. Demographic and anthropometric characteristics of 78 patients with type 2 diabetes mellitus divided into two groups with and without nonalcoholic fatty liver disease (NAFLD)

\begin{tabular}{|c|c|c|c|c|c|}
\hline \multirow{2}{*}{ Variables } & \multirow{2}{*}{$\begin{array}{c}\text { Average (SD) } \\
\text { Total }\end{array}$} & \multirow{2}{*}{$\begin{array}{l}\text { Variation } \\
\text { (min-max) }\end{array}$} & \multicolumn{2}{|c|}{ NAFLD } & \multirow{2}{*}{ p-value } \\
\hline & & & Absent & Present & \\
\hline Age (years) & $57.3(10.3)$ & $31-77$ & $57.1 \pm 10.9$ & $57.6 \pm 9.5$ & $0.818^{\top}$ \\
\hline Weight (kg) & $71.8(14.4)$ & $48-124$ & $66.0 \pm 11.7$ & $79.8 \pm 14.1$ & $<0.001^{\top}$ \\
\hline Height (m) & $1.6(0.1)$ & $1.4-1.8$ & $1.5 \pm 0.1$ & $1.6 \pm 0.1$ & $0.039^{\top}$ \\
\hline $\mathrm{BMI}\left(\mathrm{kg} / \mathrm{m}^{2}\right)$ & $29.5(4.8)$ & $20.6-39.7$ & $27.7 \pm 4.4$ & $31.9 \pm 4.3$ & $<0.001^{\top}$ \\
\hline Waist (cm) & $100.8(11,8)$ & 75-130 & $96.4 \pm 11.0$ & $106.8 \pm 10.3$ & $<0.001^{\top}$ \\
\hline Hip (cm) & $104.4(10.5)$ & $85-149$ & $100.3 \pm 8.0$ & $110 \pm 11$ & $<0.001^{\top}$ \\
\hline W/H & $1.0(0.1)$ & $0.8-1.1$ & $1.0 \pm 0.1$ & $1.0 \pm 0.1$ & $0.432^{\top}$ \\
\hline
\end{tabular}

BMI: body Mass Index; W/H-Waist/hip ratio.

T: student-T test.

Table 3. Laboratory data of 78 patients with type 2 diabetes mellitus divided into two groups with and without non-alcoholic fatty liver disease (NAFLD)

\begin{tabular}{|c|c|c|c|c|c|}
\hline \multirow{2}{*}{ Variable } & \multirow{2}{*}{ Average (SD) } & \multirow{2}{*}{$\begin{array}{l}\text { Variation } \\
\text { (min-max) }\end{array}$} & \multicolumn{2}{|c|}{ NAFLD } & \multirow{2}{*}{ p-value } \\
\hline & & & Absent & Present & \\
\hline Fasting glucose (mg/dL) & $175.8(74.2)$ & $61.2-474$ & $174.5 \pm 81.3$ & $177.7 \pm 64.4$ & $0.344^{\mathrm{MW}}$ \\
\hline Post-prandial glucose (mg/dL) & $217.6(114.4)$ & $87.4-575$ & $225.9 \pm 131.5$ & $206 \pm 85.3$ & $0.672^{\mathrm{MW}}$ \\
\hline $\mathrm{HbA1c}(\mathrm{mg} / \mathrm{dL})$ & $8.8(2.7)$ & $5.7-22.8$ & $8.8 \pm 3.0$ & $8.8 \pm 2.1$ & $0.605^{\mathrm{MW}}$ \\
\hline Total-c (mg/dL) & $204.7(49.5)$ & $87.8-359.4$ & $211.3 \pm 51.5$ & $195.9 \pm 46.0$ & $0.177^{\top}$ \\
\hline $\mathrm{HDL}-\mathrm{c}(\mathrm{mg} / \mathrm{dL})$ & $48.4(10.4)$ & $23.6-80.1$ & $48.7 \pm 9.9$ & $48.0 \pm 11.2$ & $0.781^{\top}$ \\
\hline LDL-c (mg/dL) & $122.3(41.3)$ & $46-252$ & $129.8 \pm 42.4$ & $112.2 \pm 38.0$ & $0.064^{\top}$ \\
\hline Triglycerides (mg/dL) & $164.1(84.4)$ & $35.4-455.6$ & $148.7 \pm 87.4$ & $185 \pm 76.4$ & $0.060^{\top}$ \\
\hline Uric acid (mg/dL) & $4.4(1.6)$ & $2.0-7.9$ & $4.1 \pm 1.4$ & $4.9 \pm 1.8$ & $0.041^{\top}$ \\
\hline AST (U/L) & $18.9(5.7)$ & $11-44$ & $17.8 \pm 6.0$ & $20.3 \pm 4.9$ & $0.006^{\mathrm{MW}}$ \\
\hline $\operatorname{ALT}(\mathrm{U} / \mathrm{L})$ & $21.8(10.3)$ & $7.0-65.0$ & $19.1 \pm 9.0$ & $25.4 \pm 11.0$ & $0.002^{\mathrm{MW}}$ \\
\hline AST/ALT & $1.0(0.4)$ & $0.4-2.9$ & $1.1 \pm 0.5$ & $0.9 \pm 0.2$ & $0.134^{\mathrm{MW}}$ \\
\hline Alk. phosphatase (U/L) & $93.8(28.3)$ & $42-176$ & $95.1 \pm 29.8$ & $92.0 \pm 26.4$ & $0.635^{\top}$ \\
\hline $\mathrm{GGT}(\mathrm{U} / \mathrm{L})$ & $50.5(54.2)$ & $13-337$ & $39.1 \pm 26.4$ & $66.0 \pm 59.4$ & $0.001^{\mathrm{Mw}}$ \\
\hline Bilirubin (mg/dL) & $0.5(0.2)$ & $0.1-1.3$ & $0.5 \pm 0.2$ & $0.5 \pm 0.3$ & $0.284^{\top}$ \\
\hline INR & $1.0(0.1)$ & $0.9-1.2$ & $1.0 \pm 0.1$ & $1.0 \pm 0.1$ & $0.197^{\top}$ \\
\hline Ferritin $(\mu \mathrm{g} / \mathrm{L})$ & $177.9(164.9)$ & $1.5-798$ & $152.8 \pm 137.5$ & $212.2 \pm 193.1$ & $0.144^{\mathrm{MW}}$ \\
\hline TNF- $\alpha(p g / m L)$ & $10.9 \pm 7.3$ & $0.7-30.1$ & $9.8 \pm 7.8$ & $12.4 \pm 6.4$ & $0.052^{\mathrm{MW}}$ \\
\hline Insulin (mU/L) & $14.8 \pm 17.8$ & $1.1-102.9$ & $10.3 \pm 10.4$ & $20.9 \pm 23.3$ & $0.004^{\mathrm{Mw}}$ \\
\hline HOMA-IR & $6.9 \pm 12.0$ & $0.5-96.9$ & $4.4 \pm 4.4$ & $10.2 \pm 17.4$ & $0.007^{\mathrm{MW}}$ \\
\hline
\end{tabular}

Total-c: total cholesterol; HbA1c: glicated hemoglobin; INR: prothrombin time international normalized ratio; ALT: alanine aminotranferase; AST: aspartate aminotransferase; GGT: gamma-glutamyl transpeptidase; TNF- $\alpha$ : tumor necrosis factor alpha; HOMA-IR: homeostasis model assessment of insulin resistance; MW: Mann-Whitney; T: student-T test. 
Table 4. Frequency of altered laboratory test results of 78 patients with ype 2 diabetes mellitus who presented differences when divided into two groups with and without non-alcoholic fatty liver disease (NAFLD)

\begin{tabular}{lcccc}
\hline & & \multicolumn{2}{c}{ NAFLD } & \\
\cline { 3 - 4 } Variables* & N total & $\begin{array}{c}\text { Absent } \\
(\mathbf{n = 4 5})\end{array}$ & $\begin{array}{c}\text { Present } \\
(\mathbf{n = 3 3})\end{array}$ & p-value \\
\hline $\begin{array}{c}\text { Triglycerides } \\
\text { Elevated }\end{array}$ & $39(50 \%)$ & $17(37.8 \%)$ & $22(66.7 \%)$ & $0.012^{0}$ \\
$\begin{array}{c}\text { AST/ALT } \\
>1\end{array}$ & $29(37.7 \%)$ & $21(46.7 \%)$ & $8(24 \%)$ & $0.053^{0}$ \\
$\begin{array}{c}\text { Ferritin } \\
\text { Elevated }\end{array}$ & $24(30.8 \%)$ & $10(22.2 \%)$ & $14(42.4 \%)$ & $0.056^{0}$ \\
$\begin{array}{c}\text { Insulin } \\
\text { Elevated }\end{array}$ & $4(5.1 \%)$ & $0(0 \%)$ & $4(12.1 \%)$ & $0.029^{F}$ \\
$\begin{array}{c}\text { HOMA-IR } \\
\text { Elevated }\end{array}$ & $38(48.7 \%)$ & $16(35.6 \%)$ & $22(66.7 \%)$ & $0.007^{0}$ \\
\hline
\end{tabular}

AST: aspartate aminotransferase; ALT: alanine aminotranferase; * Normal ranges: triglycerides $\leq 150 \mathrm{mg} / \mathrm{dL} ; \mathrm{ALT}: \leq 41 \mathrm{U} / \mathrm{L}$ in male and $\leq 31 \mathrm{U} / \mathrm{L}$ in female; $A S T: \leq 35 \mathrm{U} / \mathrm{L}$ in male and $\leq 31 \mathrm{U} / \mathrm{L}$ in female; Ferritin: $\leq 365 \mathrm{ng} / \mathrm{mL}$ in male and $\leq 148 \mathrm{ng} / \mathrm{mL}$ in female; Insulin: $\leq 23 \mathrm{mU} / \mathrm{L} ;$ HOMA$\mathbb{R} \leq 3.9$ in male and $\leq 3.5$ in female.

F: Fisher's Exact Test; Q: Pearson Chi-square test.

\section{DISCUSSION}

Previous research has identified NAFLD in $21 \%$ to $78 \%$ of patients suffering from DM2 $(21,22)$. The present study diagnosed NAFLD in $42 \%$ of the patients with DM2, although this frequency may have been even higher, given that lower grade of NAFLD may go unnoticed by US (2). US is around $90 \%$ sensitive and $100 \%$ specific in diagnosing NAFLD (23).

Neither age nor sex presented any relation to the occurrence of NAFLD, neither did smoking or exercise, as confirmed by other studies (7,24-26). Other interesting data was the diagnosis of hypertension in the majority $(90 \%)$ of patients with NAFLD, very probably related to the BMI, which was also higher in patients with NAFLD. It is worth noting that when NAFLD is associated with DM2, obesity, hypertension and dyslipidemia there is an increased risk of it progressing to end-stage liver disease, and a greater chance of cardiovascular diseases $(7,27)$.

In the present study, increased weight, BMI and waist measurement were more prevalent in patients with NAFLD, situations in which the IR is a predominant factor $(6,28)$. It should be highlighted that the researcher who diagnosed NAFLD using US may have been influenced by the biotypes of the patients, thus identifying liver disease with greater frequency in overweight or obese patients. Despite this unavoidable bias, the examiner followed all ultrasonographic criteria in order to diagnose fatty liver disease (17).
Although MS was diagnosed in the majority of patients within this study, it was more frequent in those with NAFLD than those without $(\mathrm{p}=0.019)$, as described above. These findings suggest that NAFLD constitutes the hepatic expression of MS and that when associated with visceral obesity and hypertension it may be employed as one of the diagnostic criteria for this syndrome $(28,29)$.

In our study, no significant differences were encountered amongst patients with or without NAFLD in relation to levels of pre- and post-prandial glucose, HbAlc, cholesterol profile, AP, bilirubin and INR. Similar serum levels of blood glucose may be because all the patients included in the two groups presented DM2. In addition, evaluating patients with non-alcoholic steatohepatitis (NASH), Poynard and cols. (30) did not also find differences in serum levels of cholesterol and bilirubins among patients with and without NASH.

Higher levels of triglycerides were more observed in patients with NAFLD, which may possibly reflect a greater accumulation of fatty acid into the liver, higher IR and a greater tendency to develop into NASH (23). In fact, patients with DM2 present a particular type of dyslipidemia with higher triglycerides and lower HDL-c levels, and patients with NAFLD also present the same lipid profile $(31,32)$.

The blood levels of uric acid were higher in $33 \mathrm{pa}-$ tients with NAFLD, and there were also described higher levels of uric acid in patients with visceral adiposity and $\operatorname{IR}(33,34)$. A recent study described the association of NAFLD with hyperuricemia and a higher risk of coronary disease (35).

Also encountered in this study were significantly higher levels of ALT, AST and $\gamma$-GT in patients with NAFLD, which could be a consequence of hepatic aggression resulting from the infiltration of fatty acids, bringing about inflammatory stimulus. Data published in the "Third National Health and Nutrition Survey" illustrate a significant association between high levels of ALT and IR, and DM2 and MS (36). It should be noted that the levels of aminotransferases in patients with NAFLD were higher than in those patients without, but the mean levels of both groups were below the upper limits of normality. These findings suggest that the normal limits of aminotransferases need to be reduced. It should be remembered that when the current limits were originally established, around 25 years ago, it is probable that certain individuals must have been considered "healthy" when in fact they were patients suffering from undiagnosed NAFLD (37). 
On the other hand, the mean serum levels of $\gamma$-GT were above the normal limits in those with NAFLD. In effect, $\gamma$-GT is linked to sedentarism, obesity, hypertension, hyperinsulinemia, dyslipidemia, oxidative inflammation and stress (38). High concentrations of $\gamma$-GT were also found in association with hypertension and central adiposity, suggesting a potentially pathogenic relationship between NAFLD, endothelial dysfunction and cardiovascular risk (38).

When the AST/ALT ratio is greater than the unity, it is indicative of more advanced liver disease, with more intense fibrosis (6). No significant difference in the AST/ALT ratio of either group was encountered in this study, although there was a tendency for this ratio to alter, above the unity, in those without NAFLD, probably because of higher levels of ALT in patients with NAFLD (Table 4).

No differences were observed in the serum levels of ferritin between the two groups, although there was a more frequent tendency $(\mathrm{p}=0.056)$ for altered levels in patients with NAFLD (Table 4). Higher levels of ferritin were discovered in patients with increased visceral fat or MS and, when the higher levels of protein were associated to advanced age, BMI $>30 \mathrm{~kg} / \mathrm{m}^{2}$ and DM2, there was a greater risk of developing liver fibrosis $(36,37,39)$.

HOMA-IR was used in this study as a method to evaluate the degree of IR. Its values were significantly higher in patients with NAFLD compared to those without NAFLD ( $\mathrm{p}=0.007)$. This finding reflects a more accentuated degree of IR in patients with NAFLD, as has already been described in the literature $(40,41)$.

Even in patients without DM2, the IR determined by HOMA-IR is associated to a higher grade of fat accumulation in patients with NAFLD (42). IR exacerbates NAFLD by means of two mechanisms. Peripherally, through the compromised distribution of fatty acids, thus overloading the liver, and in the liver itself because of the alteration to lipid metabolism, where these fatty acids undergo extra-mitochondrial (abnormal) oxidation, leading to oxidative stress (43).

The release of reactive particles of oxygen generated in oxidative stress may increase mitochondrial damage in hepatocytes and expand extra-mitochondrial oxidation of fatty acids. They may also stimulate neighboring macrophages (Kupffer cells) and release TNF- $\alpha$ which interferes with insulin sensitivity and increases its resistance (5). For the progression of NAFLD an alteration in the balance between two antagonic adipokines is important, in other words, TNF- $\alpha$ and the adiponectin, a hormone which acts to sensitize insulin, increases smooth muscle glucose uptake, and free fatty acid oxidation, decreases hepatic glucose production and decreases intracellular triglycerides (41). TNF- $\alpha$ is the cytokine that most contributes to liver damage (33). In NAFLD, serum levels of adiponectin are low, however, in some studies TNF- $\alpha$ serum levels are not elevated $(42,43)$. In this study, levels of TNF- $\alpha$ were slightly higher in patients with NAFLD $(\mathrm{p}=0.052)$.

In conclusion, our findings demonstrate that NAFLD was diagnosed by US in almost half the patients with DM2. The risk factors associated to NAFLD were elevated weight, BMI and waist measurement, hypertension and metabolic syndrome, as well as higher levels of aminotransferases, $\gamma$-GT, uric acid, TNF- $\alpha$, insulin and HOMA-IR.

Disclosure: no potential conflict of interest relevant to this article was reported.

\section{REFERENCES}

1. Bellentani S, Marino M. Epidemiology and natural history of nonalcoholic fatty liver disease (NAFLD). Ann Hepatol. 2009;8(1):S4-8.

2. Tolman KG, Fonseca V, Dalpiaz A, Tan MH. Spectrum of liver disease in type 2 diabetes and management of patients with diabetes and liver disease. Diabetes Care. 2007;30(3): 734-43.

3. BRASIL. Ministério da Saúde. Multicenter study about the prevalence of diabetes mellitus in Brazil. Accessed on: 2009 Mar 3. Available from: http://bases.bireme.br.

4. Wild S, Roglic G, Green A, Scref R, King H. Global prevalence of diabetes. Diabetes Care. 2004;27(5):1047-53.

5. Neuschwander-Tetri BA, Caldwell SH. Nonalcoholic steatohepatitis: summary of an AASLD Single Topic Conference. Hepatology. 2003;37(5):1202-19.

6. Adams LA, Angulo P, Lindor KD. Nonalcoholic fatty liver disease. CMAJ. 2005;172(7):899-905.

7. Wang Y, Zhou M, Lam K, Xu A. Protective roles of adiponectin in obesity-related fatty liver diseases: mechanisms and therapeutic implications. Arq Bras Endocrinol Metabol. 2009;53(2):201-12.

8. Bugianesi E, Bellentani S, Bedogni G, Tiribelli C, Sigliat-Baroni G, Crocè LS, et al. Clinical update on non-alcoholic fatty liver disease and steatohepatitis. Ann Hepatol. 2008;7(2):157-60.

9. Amarapurkar DN, Amarapurkar AD, Patel ND, Agal S, Baigal R, Gupte $\mathrm{P}$, et al. Nonalcoholic steatohepatitis (NASH) with diabetes: predictors of liver disease. Ann Hepatol. 2006;5(1):30-3.

10. Prashanth M, Ganesh HK, Vimal MV, John M, BangdarT, Joshi SR, et al. Prevalence of non-alcoholic fatty liver disease in patients with type 2 diabetes mellitus. JAPI 2009;57(3):205-10.

11. Garcia-Compean D, Jaquez-Quintana JO, Gonzalez-Gonzalez JA. Liver cirrhosis and diabetes: risk factores, pathophisiology, clinical implications and managment. World J Gastroenterol. 2009;15(3):280-8.

12. Marco R, Locatelli F, Zoppini G, Verlato G, Bonora E, Muggeo M. Cause-specific mortality in type 2 diabetes: The Verona Diabetes Study. Diabetes Care. 1999;22(5):756-61. 
13. Targher G, Bertolini L, Padovani R, Rodella S, Tessari R, Zenari $L$, et al. Prevalence of nonalcoholic fatty liver disease and its association with cardiovascular disease among type 2 diabetic patients. Diabetes Care. 2007;30(5):1212-8.

14. Lautämaki R, Borra R, lozzo P, Komu M, Lehtimaki T, Salmi M, et al. Liver steatosis coexists with myocardial insulin resistance and coronary dysfunction in patients with type 2 diabetes. Am J Physiol Enddocrinol Metab. 2006;291(2):E282-90.

15. Targher G, Bertolini L, Rodella S, Zoppin G, Lippi G, Day C, Muggeo M. Non-alcoholic fatty liver disease is independently associated with an increased prevalence of chronic kidney disease and proliferative/laser-treated retinopathy in type 2 diabetic patients. Diabetologia. 2008;51(3):444-50.

16. Chew GT, Gan SK, Watts GF. Revisiting the metabolic syndrome. MJA. 2006;185(8):445-9.

17. International Diabetes Federation 2005. IDF Consensus Worldwide Definition of the Metabolic Syndrome. Accessed on: Mar 23 2009. Available from: http://www.idf.org.br.

18. Hamer WO, Aguirre DA, Casola G, Lavine JE, Woenckhaus M, Sirlin CB. Fatty liver: imaging patterns and pitfalls. Radiographics. 2006;26(6):1637-53.

19. Zander R, Lang W, Wolf HU. Alkaline haematin D-575, a new tool for the determination of haemoglobin as an alternative to the cyanhaemiglobin method. I. Description of the method. Clin Chim Acta. 1984;136(1):83-93.

20. Geloneze B, Vasques AC, Stable CF, Pareja JC, Rosado LE, Queiroz EC, et al. HOMA1-IR and HOMA2-IR indexes in identifying insulin resistance and metabolic syndrome: Brazilian Metabolic Syndrome Study (BRAMS). Arq Bras Endocrinol Metabol. 2009;53(2):281-7.

21. McCullough AJ. Update on nonalcoholic fatty liver disease. J Clin Gastroenterol. 2002;34(3):255-62.

22. Marchesini G, Brizi M, Bianchi G, Bianchi G, Bugianesi E, McCullough AJ, et al. Association of nonalcoholic fatty liver disease with insulin resistance. Am J Med. 1999(5);107:450-5.

23. Hamaguchi $M$, Kojima T, Itoh Y, Yuichi H, Kota F, Tomoaki N, et al. The severity of ultrasonographic finding in nonalcoholilic fatty liver disease reflects the metabolic syndrome and visceral fat accumulation. Am J Gastroenterol. 2007;102(12):2708-15.

24. Schreuder T, Verwer BJ, van Nieuwkerk MJC, Mulder JJC. Nonalcoholic fatty liver disease: an overview of current insights in pathogenesis, diagnosis and treatment. World J Gastroenterol. 2008;14(16):2474-86.

25. Kang H, Greenson JK, Omo JT, Chao C, Peterman D, Anderson L, et al. Metabolic syndrome is associated with greater histologic severity, higher carbohydrate, and lower fat diet in patients with NAFLD. Am J Gastroenterol. 2006;101(10):2247-53.

26. Bedogni G, Miglioli L, Matsutti F, Tiribelli C, Marchesini G, Bellentani. Prevalence of and risk factors for nonalcoholic fatty liver disease: the Dionysos nutrition and liver study. Hepatology. 2005;42(1):44-52.

27. Lizardi-Cevera L, Aguilar-Zapata D. Nonalcoholic fatty liver disease and its association with cardiovascular disease. Ann Hepatol. 2009;8(1):S40-3.
28. Tarantino G. Should nonalcoholic fatty liver disease be regarded as a hepatic illness only? World J Gastroenterol. 2007;13(35):4669-72.

29. Kotronen A, Yki-Järvinen H. Fatty liver: a novel component of the metabolic syndrome. ArteriosclerThromb Vasc Biol. 2008;28(1):27-38.

30. Poynard T, Ratziu V, Charlotte F, Messous D, Munteanu M, Imbert-Bismut $F$, et al. Diagnostic value of biochemical markers (NashTest) for the prediction of non alcoholo steato hepatitis in patients with non-alcoholic fatty liver disease. BMC Gastroenterol. 2006;6(11):34-50.

31. Adiels M, Olofsson SO, Taskinen MR, Boren J. Diabetic dyslipidaemia. Current Opin Lipidol. 2005;16:421-7.

32. Toledo GF, Sniderman DA, Kelley ED. Influence of hepatic steatosis (fatty liver) on severity and composition of dyslipidemia in type 2 diabetes. Diabetes Care. 2006;29(8):1845-50.

33. Li Y, Xu C, Yu C, Xu L, Miao M. Association of serum uric acid level with non-alcoholic fatty liver disease: a cross-sectional study. J Hepatol. 2009;50(5):1029-34.

34. Fenkci S, Rota S, Sabir N, Akdag B. Ultrasonographic and biochemical evaluation of visceral obesity in obese women with nonalcoholic fatty liver disease. Eur J Med Res. 2007;12(2):68-73.

35. Baba T, Amasaki Y, Soda M, Hida A, Imaizumi M, Nakashima E, et al. Fatty liver and acid uric levels predict incident coronary heart disease but not stroke among atomic bomb survivous in Nagasaki. Hypertens Res. 2007;30(9):823-9.

36. Liangpunsakul S, Chalasani N. Unexplained elevations in alanine aminotransferase in individuals with the metabolic syndrome: results from the Third National Health and Nutrition Survey (NHANES III). Am J Med Sci. 2005;32(3):111-6.

37. Prati D, Taioli E, Zanalla A, Della Torre E, Butelli S, Del Vecchio E, et al. Updated definitions of healthy ranges for serum alanine aminotransferase levels. Ann Int Med. 2002;137(1):1-9.

38. Stranges S, Trevisan M, Dorn JM, Dmochowski J, Donahue RP. Body distribution, liver enzymes, and risk of hypertension: evidence from the Western New York Study. Hypertension. 2005;46(5):1186-93.

39. Trombini P, Piperno A. Ferritin, metabolic syndrome and NAFLD: elective attractions and dangerous liasions. J Hepatol. 2007;46(4):549-52.

40. Lyssenko V, Almgren P, Anevski D, Perfekt R, Lahti K, Nissén M, et al. Predictors of and longitudinal changes in insulin sensitivity and secretion preceding onset of type 2 diabetes. Diabetes. 2005;54(1):166-74.

41. Wajchenberg BL, Nery M, Cunha MR, Silva ME. Adipose tissue at the crossroads in the development of the metabolic sindrome, inflammation and aterosclerosis. Arq Bras Endocrinol Metabol. 2009;53(2):145-50.

42. Perez-Carreras M, Del Hoyo P, Marti MA, Rubio CJ, Martin A, Castellano $G$, et al. Defective hepatic mitochondrial respiratory chain in patients with nonalcoholic steatohepatitis. Hepatology. 2003;38(4):999-1007.

43. Aller R, de Luis DA, Fernandez L, Calle F, Velayos B, Olcos JL, et al. Influence of insulin resistance and adipokines in the grade of steatosis of nonalcoholic fatty liver disease. Dig Dis Sci. 2008;53(4):1088-92. 